\title{
Blickdiagnose
}

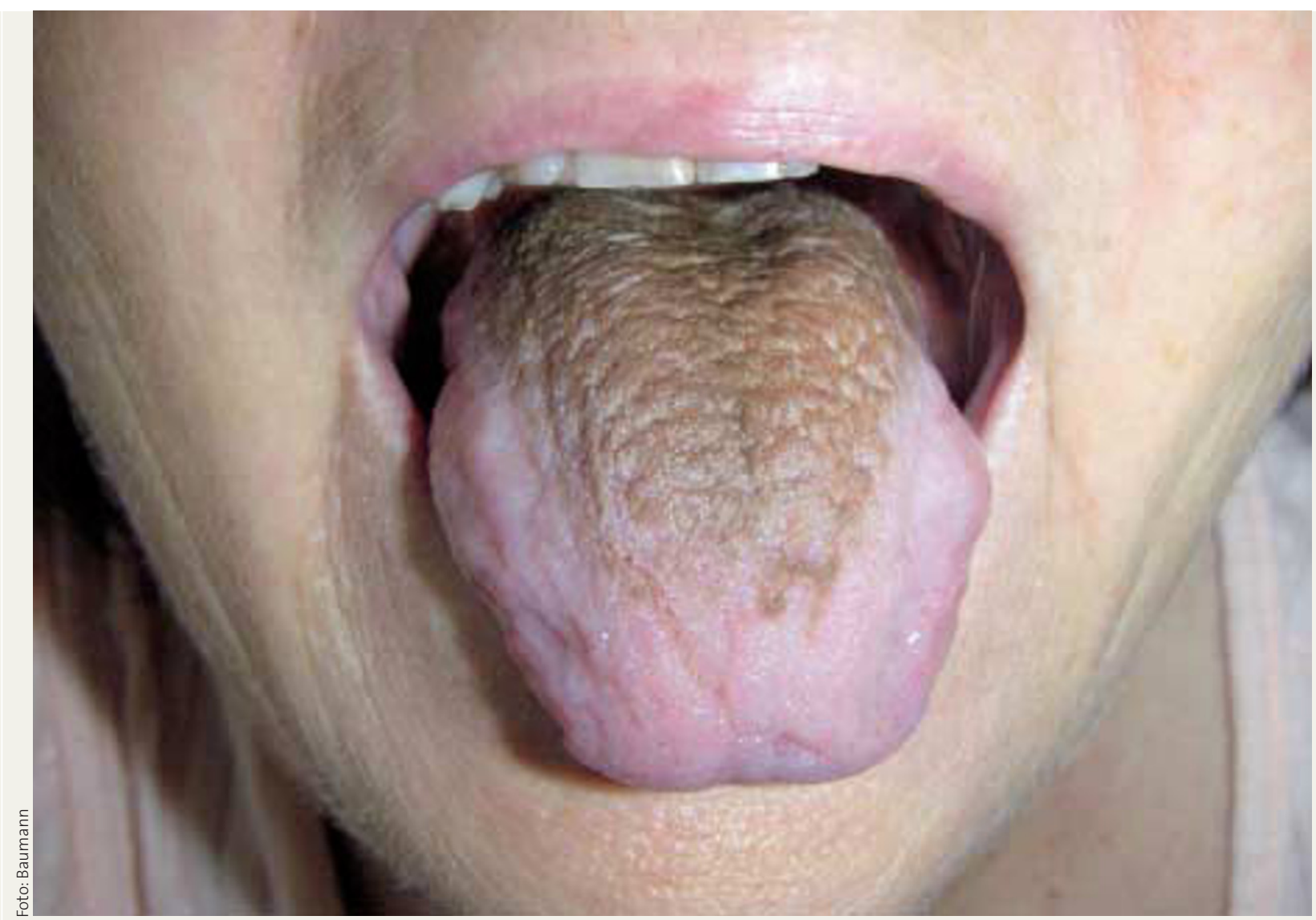

\section{„Haare auf der Zunge“}

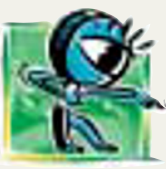

Als schwarze Haarzunge (Nigritis linguae; lingua villosa nigra; black hairy tongue) wird eine sehr seltene Erkrankung der Zunge bezeichnet. Hervorgerufen wird sie durch die Verlängerung der Papillae filiformes der Zunge, die einen haarigen und meist dunklen Belag auf dem hinteren Teil des Zungenrückens bilden. Je nach aufgenommener Nahrung nimmt die Zunge eine dunkelgrüne bis schwärzliche Färbung an. Die Ursache der Erkrankung ist unbekannt. Es wird eine Veränderung der Mundhöhlenflora vermutet, z. B. durch Antibiotikatherapie, Nikotinmissbrauch, Niacinmangel, Pilzbefall oder Lebererkrankungen.

In unserem Fall fiel die Patientin mit rezidivierenden Fieberschüben und Luftnot auf, die auch durch verschiedene Antibiotikatherapien nicht zu beeinflussen waren. Ob die Schwarzfärbung der Zunge bereits vor der Antibiotikagabe eintrat, war retrospektiv nicht mehr zu eruieren. Bei kleinem Pleuraerguss wurde im CT-Thorax die Verdachtsdiagnose Pilzpneumonie gestellt. Die Bronchiallavage und Pleurapunktion erbrachten keinen Pilznachweis. Auf Antimykotika erholte sich die Patientin rasch und die Schwarzfärbung verschwand innerhalb einer Woche.

- Dr. med. Roland Baumann, Facharzt für Allgemeinmedizin, D-19370 Parchim

\section{Ihr besonderer Fall?}

Sicher sehen auch Sie ab und an einen besonders eindrucksvollen Befund in Ihrer Praxis. Fotografieren Sie ihn, schreiben Sie uns unter dem Stichwort Blickdiagnose, bei Veröffentlichung erhalten Sie 100 Euro.

MMW-Fortschritte der Medizin

E-Mail: manhart@urban-vogel.de

Fax: 089/4372-1420

Weitere interessante Blickdiagnosen finden Sie in unserem Online-Archiv unter www.mmw.de. 